\title{
OPEN Different types of agricultural land use drive distinct soil bacterial communities
}

\author{
Shin Ae Lee ${ }^{1,6}$, Jeong Myeong Kim²,6, Yiseul Kim ${ }^{1}$, Jae-Ho Joa ${ }^{3}$, Seong-Soo Kang ${ }^{4}$, \\ Jae-Hyung Ahn ${ }^{1}$, Mincheol Kim ${ }^{5}$, Jaekyeong Song ${ }^{1} \&$ Hang-Yeon Weon ${ }^{1 \bowtie}$
}

Biogeographic patterns in soil bacterial communities and their responses to environmental variables are well established, yet little is known about how different types of agricultural land use affect bacterial communities at large spatial scales. We report the variation in bacterial community structures in greenhouse, orchard, paddy, and upland soils collected from 853 sites across the Republic of Korea using 16S rRNA gene pyrosequencing analysis. Bacterial diversities and community structures were significantly differentiated by agricultural land-use types. Paddy soils, which are intentionally flooded for several months during rice cultivation, had the highest bacterial richness and diversity, with low community variation. Soil chemical properties were dependent on agricultural management practices and correlated with variation in bacterial communities in different types of agricultural land use, while the effects of spatial components were little. Firmicutes, Chloroflexi, and Acidobacteria were enriched in greenhouse, paddy, and orchard soils, respectively. Members of these bacterial phyla are indicator taxa that are relatively abundant in specific agricultural land-use types. A relatively large number of taxa were associated with the microbial network of paddy soils with multiple modules, while the microbial network of orchard and upland soils had fewer taxa with close mutual interactions. These results suggest that anthropogenic agricultural management can create soil disturbances that determine bacterial community structures, specific bacterial taxa, and their relationships with soil chemical parameters. These quantitative changes can be used as potential biological indicators for monitoring the impact of agricultural management on the soil environment.

Diverse soil microbes play critical roles in plant growth and health. They decompose organic compounds and participate in the recycling of nutrients, such as nitrogen, phosphorus, and potassium, which are important for plant growth ${ }^{1-3}$. Some soil microbes in the rhizosphere and endosphere of plants improve tolerance to abiotic and biotic stress ${ }^{4}$. In addition to physicochemical properties of soils, soil microbial communities largely determine agricultural productivity ${ }^{5}$. To develop sustainable agriculture, understanding of ecological features of microbiomes in agroecosystems is needed.

The biogeography of soil microbial communities has been investigated at various spatial scales. Fierer and Jackson (2006) observed that microbial biogeography is primarily controlled by edaphic variables, not geographic distance. Another study of microbial communities in soils collected across the state of California, USA, showed that land-use types such as coastal grasslands, inland grasslands, deserts, coniferous forests, freshwater wetlands, and perennial and annual agricultural fields were closely associated with distinct microbial communities at a regional level ${ }^{6}$. A more recent and detailed characterization of soil microbial communities reported different biogeographic patterns of soil microbial communities across natural forests with vegetation gradients and distinct edaphic variables ${ }^{7}$. Different patterns of microbial diversity across different habitats (e.g., alpine grassland, desert, desert grassland, and typical grassland) were also observed in the drylands of northern China ${ }^{8}$. These investigations together suggest that the types of habitats or land use affect biogeographic patterns of bacterial taxa from regional to continental scales.

\footnotetext{
${ }^{1}$ Agricultural Microbiology Division, National Institute of Agricultural Sciences, Rural Development Administration, Wanju, Republic of Korea. ${ }^{2}$ Water Supply and Sewerage Research Division, National Institute of Environmental Research, Incheon, Republic of Korea. ${ }^{3}$ Research Institute of Climate Change and Agriculture, National Institute of Horticultural and Herbal Science, Rural Development Administration, Jeju, Republic of Korea. ${ }^{4}$ Soil and Fertilization Division, National Institute of Agricultural Sciences, Rural Development Administration, Wanju, Republic of Korea. ${ }^{5}$ Korea Polar Research Institute, Incheon, Republic of Korea. ${ }^{6}$ These authors contributed equally: Shin Ae Lee and Jeong Myeong Kim. ${ }^{\square}$ email: why@korea.kr
} 
A

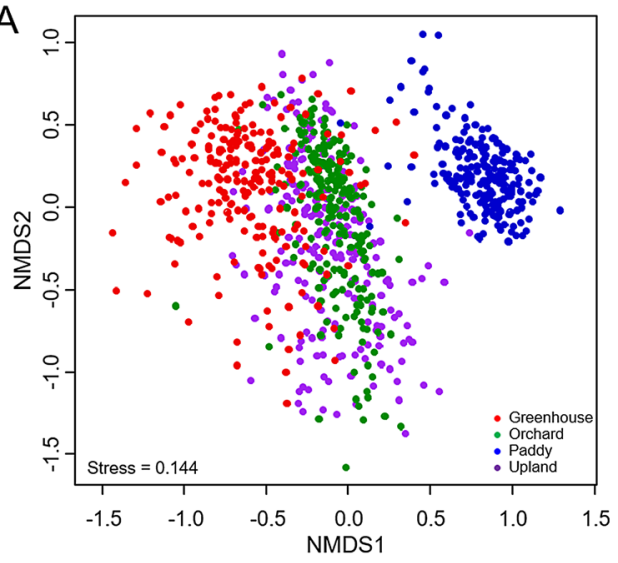

B

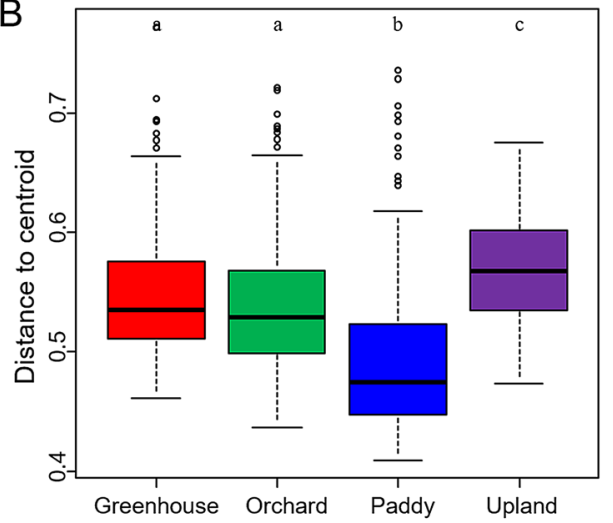

Figure 1. Beta-diversity of soil bacterial communities in the four types of agricultural land use. Non-metric multidimensional scaling (NMDS) ordination of soil bacterial communities (A). Box plot illustrating the betadispersion of bacterial communities (B). Significant differences between land-use types were tested by Tukey's HSD and are indicated by different letters $(\mathrm{P}<0.05)$. Boxes represent the interquartile range $(\mathrm{IQR})$, and whiskers indicate the furthest point within $1.5 \times \mathrm{IQR}$ above or below the IQR. Values beyond this range are plotted as individual points. The central line indicates the median.

Agricultural management such as fertilization, irrigation, and tillage are important factors that affect the biodiversity and function of terrestrial ecosystems and can also lead to soil ecosystem degradation ${ }^{9-13}$. Previous studies show that land management practices such as chemical fertilization have a significant effect on bacterial community structure ${ }^{14-16}$. Effects of soil parameters, including $\mathrm{pH}$, electrical conductivity (EC), carbon and nitrogen contents, salinity, and texture, on microbial community composition have been reported in many studies $^{17-22}$, and this relationship was shown to be significant even in unique environments, such as the black soils of Northeast China ${ }^{23-25}$.

Bacterial taxa with distinct relative abundance patterns have been proposed as potential biological indicators that reflect environmental conditions. A recent study by Hermans et al. showed that microbial communities across diverse New Zealand soil types (e.g., indigenous forest, exotic forest, horticulture, and dairy) are more sensitive to changing soil environments than to variation in climate or increased geographical heterogeneity ${ }^{26}$. They also observed certain dominant taxa to be significantly related to specific soil parameters. These results support the use of specific bacterial taxa and their relative abundances as biological indicators that can be used to predict various soil attributes (e.g., $\mathrm{pH}$, nutrient concentrations).

To explore interactions between microbial taxa in complex soil microbial ecology, co-occurrence network analysis has been widely used ${ }^{27,28}$. In the network, keystone taxa that have frequent interactions with many others are predicted to play an important role in microbial ecology ${ }^{29}$. Distinct co-occurrence patterns have been reported in different agricultural practices (organic and conventional farming) ${ }^{16}$ and habitats (bulk soil and rhizosphere) ${ }^{30}$. However, the co-occurrence networks of soil bacterial communities in different types of agricultural land use have not been explored using a large number of samples.

To elucidate the soil microbial distributions in agricultural soils, we collected 853 soil samples from four major types of agricultural land, including greenhouses, orchards, paddy fields, and uplands, throughout the Republic of Korea. We measured the edaphic factors of the soils and performed $16 \mathrm{~S}$ rRNA gene pyrosequencing analysis of bacterial communities. The specific objectives of this study were to characterize bacterial communities in different agricultural land-use types through analyses of bacterial community diversity, composition, indicator species, and co-occurrence patterns.

\section{Results}

Bacterial community variation across different agricultural land-use types. To survey bacterial communities in agricultural soils across the Republic of Korea, we collected 853 soil samples from four major types of agricultural land use: greenhouses (211), uplands (209), orchards (224), and paddy fields (209) (Supplementary Fig. S1 and Supplementary Data S1). We obtained a total of 3,616,347 high-quality sequence reads by $16 \mathrm{~S}$ rRNA gene pyrosequencing and identified 68,528 operational taxonomic units (OTUs) based on $97 \%$ sequence identity across all samples.

The variation in bacterial community structures was visualized with a nonmetric multidimensional scale (NMDS) plot based on Bray-Curtis distance. Bacterial communities in paddy soils were clearly differentiated from those in the other types of soil (Fig. 1A). Bacterial communities in greenhouse soils were also differentiated from those in orchard and upland soils. The significant differences between agricultural land-use types were confirmed by pair-wise comparison analysis of similarities (ANOSIM) and permutational multivariate analysis of variance (PERMANOVA) (Supplementary Table S1). Although bacterial communities of orchard and upland soils were closely positioned in the ordination plots (Fig. 1A), the pair-wise comparison tests were significant for all pairs of agricultural land-use types (Supplementary Table S1). The dispersion of soil bacterial 


\begin{tabular}{|l|l|l|l|l|l|l|}
\hline & & & \multicolumn{3}{l|}{ Richness estimator } & \multicolumn{2}{l|}{ Diversity index } \\
\cline { 5 - 8 } Land-use type & No. of OTUs & Coverage & Chao-1 & ACE & Shannon & Inverse-Simpson \\
\hline Greenhouse $(\mathrm{n}=211)$ & $564 \pm 80$ & $0.60 \pm 0.07$ & $1529 \pm 353^{\mathrm{b}}$ & $2566 \pm 692^{\mathrm{b}}$ & $5.9 \pm 0.3^{\mathrm{c}}$ & $340 \pm 183^{\mathrm{c}}$ \\
\hline Orchard $(\mathrm{n}=224)$ & $581 \pm 85$ & $0.59 \pm 0.08$ & $1506 \pm 366^{\mathrm{b}}$ & $2374 \pm 713^{\mathrm{c}}$ & $6.0 \pm 0.3^{\mathrm{b}}$ & $403 \pm 200^{\mathrm{b}}$ \\
\hline Paddy $(\mathrm{n}=209)$ & $623 \pm 49$ & $0.54 \pm 0.05$ & $1778 \pm 319^{\mathrm{a}}$ & $3107 \pm 855^{\mathrm{a}}$ & $6.1 \pm 0.2^{\mathrm{a}}$ & $447 \pm 157^{\mathrm{a}}$ \\
\hline Upland $(\mathrm{n}=209)$ & $514 \pm 80$ & $0.66 \pm 0.07$ & $1172 \pm 300^{\mathrm{c}}$ & $1764 \pm 585^{\mathrm{d}}$ & $5.8 \pm 0.3^{\mathrm{d}}$ & $290 \pm 147^{\mathrm{d}}$ \\
\hline
\end{tabular}

Table 1. Alpha-diversity for soil bacterial communities in the four different types of land use. The original dataset was sub-sampled to 1,002 reads. ${ }^{a-c}$ The letters in each column indicate significant differences $(\mathrm{P}<0.05$, Tukey's HSD). OTUs operational taxonomic units.

communities within each type of agricultural land use was examined by measuring the distance between the centroid. Bacterial community dissimilarity within each type of agricultural land use was the lowest in paddy soils and the highest in upland soils (Fig. 1B).

To compare alpha-diversity between the samples, the OTU dataset was sub-sampled to the smallest number of total reads within a sample (1,002 reads). Chaol and ACE richness estimators were significantly higher in paddy soils, while those in upland soils were lower (Table 1). Similarly, paddy soils showed significantly higher Shannon and inverse-Simpson diversity indices, followed by orchard, greenhouse, and upland soils. Taken together, paddy soils had significantly higher bacterial richness and diversity, with lower bacterial community variation, while upland soils harbored bacterial communities with lower richness and diversity but greater variation compared to other types of agricultural land use. Although the compositions of bacterial communities in upland and orchard soils look similar according to NMDS, the greater bacterial community variation in upland soils may partially explain the significant difference from orchard soils.

Variation in soil chemical properties across different types of agricultural land use. The principal component analysis (PCA) ordination plot showed that soil chemical properties were clearly separated between paddy and greenhouse soils along the first axis, which explains $48.9 \%$ of total variation, and those in upland and orchard soils were in between (Fig. 2A). Of the soil properties we measured, EC, available $\mathrm{P}_{2} \mathrm{O}_{5}$, and exchangeable cations $\left(\mathrm{Ca}^{2+}, \mathrm{Mg}^{2+}, \mathrm{K}^{+}\right.$, and $\left.\mathrm{Na}^{+}\right)$were significantly higher in greenhouse soils compared to soils of other types of agricultural land use, while paddy soils had significantly lower values of $\mathrm{pH}$ and available $\mathrm{P}_{2} \mathrm{O}_{5}$, $\mathrm{Mg}^{2+}$, and $\mathrm{K}^{+}$(Table 2).

Among the edaphic factors measured, bacterial richness (Chao-1) and diversity (Shannon index) had a significant association with soil pH (Fig. 2B). Bacterial richness and diversity were the highest in neutral soils and lower in acidic soil, which is consistent with previous studies that utilized a variety of biogeographical scales and land uses ${ }^{6,17,23,31,32}$. In particular, bacterial richness and diversity in orchard soils showed the strongest correlation with soil $\mathrm{pH}$, while those in paddy soils with lower $\mathrm{pH}$ levels ( $\mathrm{pH}$ 5.0-6.0) showed no significant correlation (Supplementary Fig. S2 and S3).

The redundancy analysis (RDA) ordination plot constrained by soil chemical properties also showed that bacterial communities were separated by agricultural land-use types along the first axis (Fig. 2C). The chemical properties we measured in this study explained $14.1 \%$ of the total variation. The triplots show that EC and $\mathrm{K}^{+}$are important factors in the dispersion of the bacterial communities along the first axis. We identified specific OTUs that are highly correlated with chemical properties (Pearson $r>0.5, P<0.01$ ). Only six OTUs were correlated with EC, which belonged to the families Rhodospirillaceae (OTU4130, OTU5485, OTU340, and OTU505) and Rhodobacteraceae (OTU4767) and the phylum Chloroflexi (OTU269) (Supplementary Fig. S4).

Although many studies have reported that microbial community similarity tends to decrease along increasing geographical distances ${ }^{33,34}$, no significant distance-decay patterns of bacterial communities in agricultural soils were observed (Supplementary Fig. S5). Variation partitioning analysis was performed with three explanatory components-land-use types, edaphic and spatial variables. The spatial variables were generated via Moran's eigenvector maps (MEMs) as a method of spatial eigenfunction. Variation partition analysis showed that $15.0 \%$ of the total bacterial community variation was explained by land-use type, $11.8 \%$ by edaphic variables, and $3.9 \%$ by spatial variables (Fig. 2D). Land-use type and edaphic variables jointly demonstrated $7.3 \%$ of the community variation, suggesting that a large proportion of variability in soil chemical properties are associated with the changes in the use of land. For different types of agricultural land use, edaphic variables (11.9\% in orchard, $10.2 \%$ in paddy, and $9.8 \%$ in greenhouse soils) was shown to be higher than spatial variables (6.7\% in orchard, $7.2 \%$ in paddy, and 5.9\% in greenhouse soils) (Supplementary Fig. S6). Taken together, despite the various unknown factors that influence community variation, soil chemical properties derived by agricultural land use significantly affect bacterial community structures.

Indicator taxa for specific types of agricultural land use. Of the 68,528 OTUs obtained from 853 soil samples across four types of agricultural land, 47,095 (68.7\%) OTUs were assigned to phylum-level taxa. At lower taxonomic levels, 38,572 (56.3\%), 29,381 (42.9\%), 20,198 (29.5\%), and 12,169 (17.8\%) OTUs were assigned to class, order, family, and genus, respectively. Among the 40 phyla identified in this study, eight had relative abundances greater than $1 \%$ and accounted for $81 \%$ of the total abundance, with Proteobacteria (32.7\%), Acidobacteria (14.9\%), and Actinobacteria (10.5\%) being the dominant phyla of the bacterial communities 
A

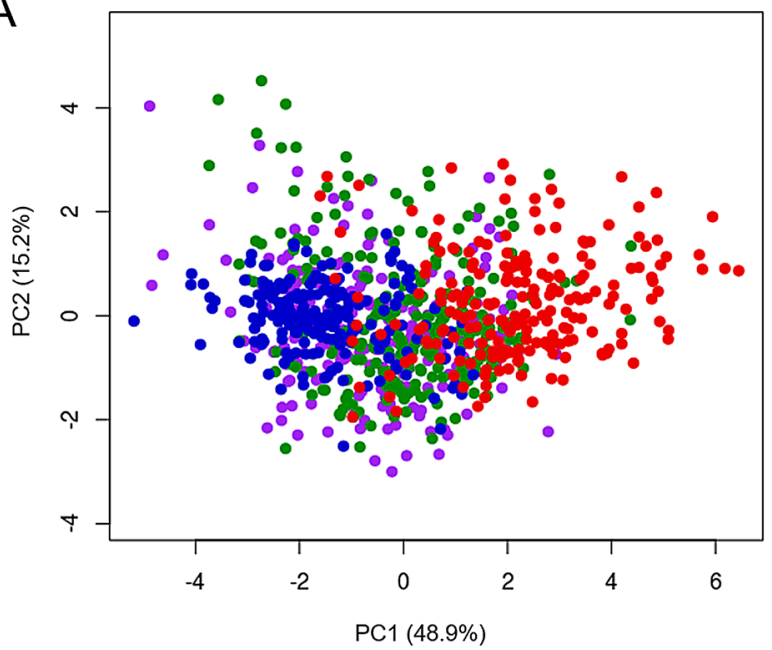

C

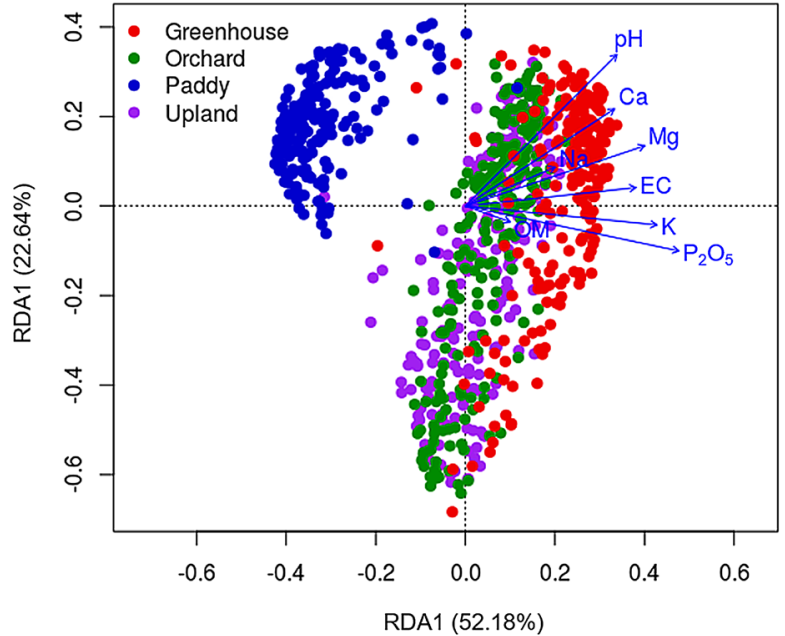

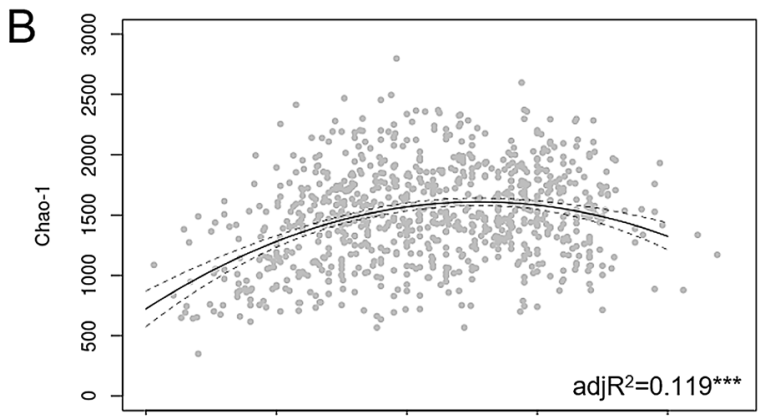

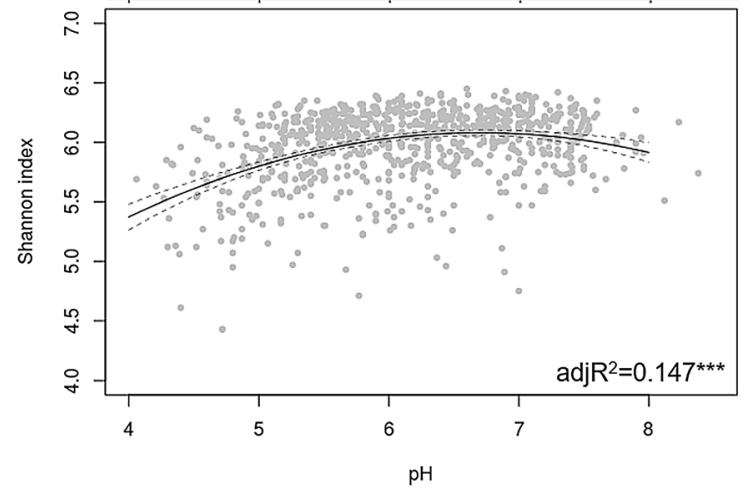

D

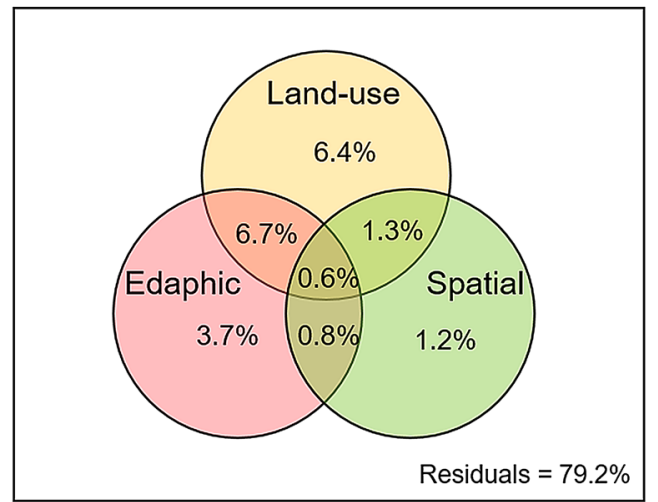

Figure 2. Soil chemical properties associated with the types of agricultural land use. Principal component analysis (PCA) of soil chemical properties using $\mathrm{z}$-transformed soil variables (A). The association of bacterial richness (Chao-1) and diversity (Shannon index) with soil $\mathrm{pH}$ in different types of agricultural soils (B). Quadratic regression was used to determine the adjusted $R^{2}$ values and statistical significances $\left({ }^{\star * \star} P<0.001\right)$. Redundancy analysis (RDA) of bacterial communities constrained by soil chemical properties $(\mathbf{C})$. The joint biplot indicates the correlation between the chemical factors and ordination scores of RDA axes. EC electrical conductivity, $O M$ organic matter. Venn diagram representing variation partitioning of bacterial communities explained by land-use types, edaphic and spatial variables (D).

\begin{tabular}{|c|c|c|c|c|c|c|c|c|c|}
\hline \multirow[b]{2}{*}{ Land-use type } & \multirow[b]{2}{*}{ Statistics } & \multirow[b]{2}{*}{ pH (1:5) } & \multirow[b]{2}{*}{$\mathrm{EC}\left(\mathrm{dS} \mathrm{m}^{-1}\right)$} & \multirow[b]{2}{*}{ OM $\left(\mathrm{g} \mathrm{kg}^{-1}\right)$} & \multirow{2}{*}{$\begin{array}{l}\text { Av. } \mathbf{P}_{2} \mathrm{O}_{5}(\mathrm{mg} \\
\left.\mathrm{kg}^{-1}\right)\end{array}$} & \multicolumn{4}{|c|}{ Ex. cation $\left(\mathrm{cmol}_{\mathrm{c}} \mathrm{kg}^{-1}\right)$} \\
\hline & & & & & & $\mathbf{K}^{+}$ & $\mathrm{Ca}^{2+}$ & $\mathrm{Mg}^{2+}$ & $\mathrm{Na}^{+}$ \\
\hline \multirow{2}{*}{$\begin{array}{l}\text { Greenhouse } \\
(\mathrm{n}=211)\end{array}$} & Mean \pm S.D & $6.5 \pm 0.8^{\mathrm{a}}$ & $3.9 \pm 3.9^{\mathrm{a}}$ & $41.0 \pm 22.6^{\mathrm{a}}$ & $1,023 \pm 576^{\mathrm{a}}$ & $1.7 \pm 1.3^{\mathrm{a}}$ & $11.4 \pm 4.7^{\mathrm{a}}$ & $3.7 \pm 1.9^{\mathrm{a}}$ & $0.9 \pm 2.1^{\mathrm{a}}$ \\
\hline & Range & $4.3-7.8$ & $0-21.0$ & $8.1-184.8$ & $57-3,018$ & $0.1-8.5$ & $0.9-28.7$ & $0.4-10.0$ & $0.1-29.1$ \\
\hline \multirow{2}{*}{$\begin{array}{l}\text { Orchard } \\
(\mathrm{n}=224)\end{array}$} & Mean \pm S.D & $6.2 \pm 0.9^{\mathrm{a}}$ & $0.7 \pm 0.8^{\mathrm{b}}$ & $38.6 \pm 29.1^{\mathrm{a}}$ & $670 \pm 391^{\mathrm{b}}$ & $0.9 \pm 0.7^{\mathrm{b}}$ & $7.5 \pm 3.7^{\mathrm{b}}$ & $2.0 \pm 1.1^{\mathrm{b}}$ & $0.2 \pm 0.2^{\mathrm{b}}$ \\
\hline & Range & $4.2-7.9$ & $0.1-7.4$ & $2.7-178.9$ & $24-1,911$ & $0.1-5.1$ & $0.5-19.4$ & $0.2-6.2$ & $0.0-0.7$ \\
\hline \multirow{2}{*}{$\begin{array}{l}\text { Paddy } \\
(\mathrm{n}=209)\end{array}$} & Mean \pm S.D & $5.8 \pm 0.6^{\mathrm{b}}$ & $0.5 \pm 0.4^{\mathrm{b}}$ & $30.1 \pm 25.5^{\mathrm{b}}$ & $139 \pm 156^{\mathrm{C}}$ & $0.3 \pm 0.2^{c}$ & $5.7 \pm 2.7^{\mathrm{c}}$ & $1.3 \pm 0.9^{c}$ & $0.3 \pm 0.3^{\mathrm{b}}$ \\
\hline & Range & $4.6-7.5$ & $0.1-2.5$ & $6.0-165.0$ & $6.3-1,098$ & $0.1-1.0$ & $0.8-20.1$ & $0.2-4.5$ & $0-2.0$ \\
\hline \multirow{2}{*}{$\begin{array}{l}\text { Upland } \\
(\mathrm{n}=209)\end{array}$} & Mean \pm S.D & $6.1 \pm 0.9^{\mathrm{a}}$ & $0.6 \pm 0.6^{\mathrm{b}}$ & $25.5 \pm 23.5^{\mathrm{b}}$ & $589 \pm 428^{\mathrm{b}}$ & $0.8 \pm 0.6^{\mathrm{b}}$ & $6.1 \pm 3.7^{\mathrm{c}}$ & $1.7 \pm 0.9^{\mathrm{b}}$ & $0.2 \pm 0.2^{\mathrm{b}}$ \\
\hline & Range & $4.1-8.4$ & $0.1-4.1$ & $4.2-236.0$ & $21-1,789$ & $0.1-3.4$ & $0.3-29.8$ & $0.1-5.6$ & $0.0-0.8$ \\
\hline
\end{tabular}

Table 2. Description of soil chemical properties in the four different types of land use. ${ }^{\mathrm{a}-\mathrm{c}}$ The letters in each column indicate significant differences ( $\mathrm{P}<0.05$, Tukey's HSD). EC electrical conductivity, OM organic matter, $C V$ coefficient of variation. 


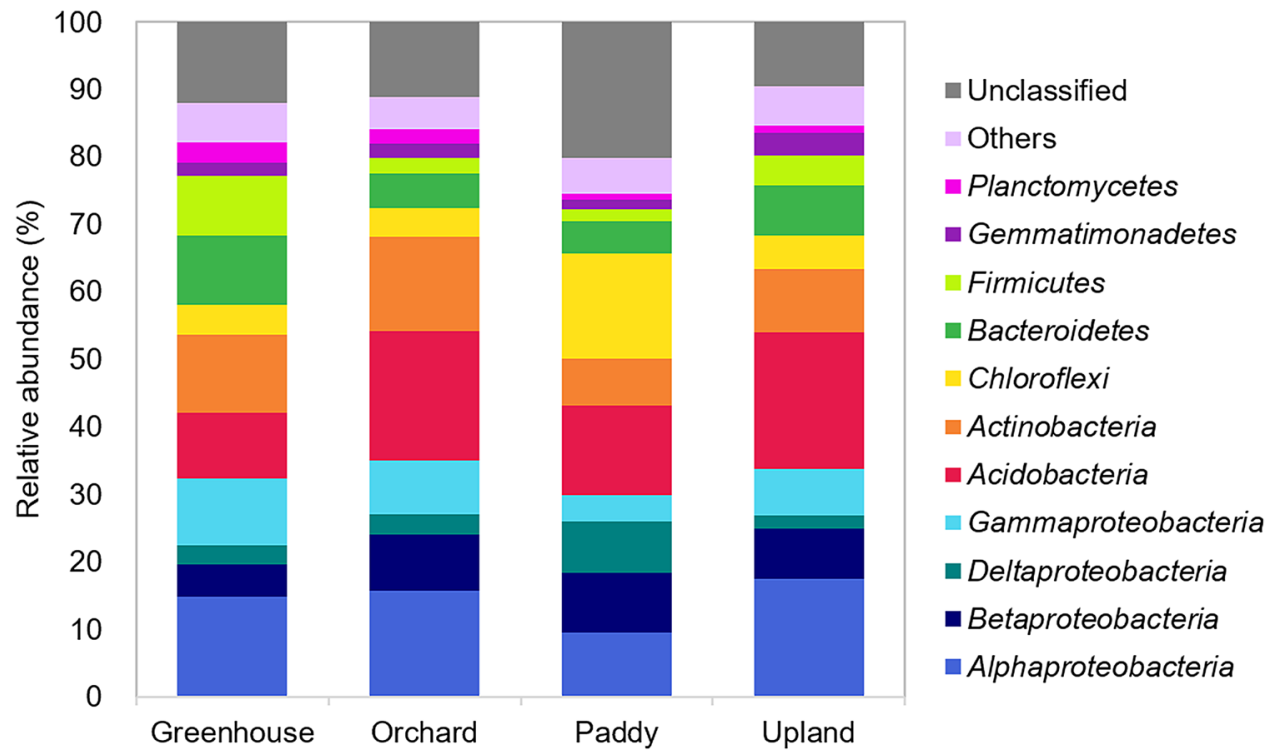

Figure 3. Taxonomic distribution of the bacterial communities in the four types of agricultural land use. The phyla with an abundance of $<1 \%$ are indicated as "others". For Proteobacteria, the classes are indicated. The stacked column bar graph was generated using Microsoft Excel software.

across soils of different agricultural land-use types (Fig. 3). Relative abundances of Bacteroidetes (10.3\%) and Firmicutes (8.8\%) were higher in greenhouse soils than in other soils, while Acidobacteria (19.1\% and $20.2 \%$, respectively) in orchard and upland soils were more abundant than the other two soils. The relative abundances of Chloroflexi (15.5\%) and Deltaproteobacteria (7.6\%) in paddy soils were two to three times higher, while that of Alphaproteobacteria (9.5\%) was lower than those of soils of the other agricultural land-use types.

To identify individual OTUs sensitive to specific agricultural land-use type, indicator species analysis was performed based on point biserial correlation. The 391 OTUs had significant associations (point biserial correlation coefficient $\mathrm{R}>0.4$ and $P<0.001$ ) with a particular agricultural land-use type or its combinations, which were illustrated with a bipartite network (Fig. 4). The sequence reads of these indictor OTUs accounted for $15.5 \%$ of the total number of sequences. Paddy soils had the most indicator OTUs (287), with a relative abundance of $25.6 \%$, followed by greenhouse (78 OTUs, with a relative abundance of $10.4 \%$ ), orchard (15 OTUs, with a relative abundance of $1.6 \%$ ), and upland (1 OTU, with a relative abundance of $0.1 \%$ ) soils, indicating that paddy soils provide a more distinctive niche than the other land-use types do. The indicator taxa of paddy soils comprised OTUs belonging mainly to the phyla Chloroflexi and Acidobacteria, and those of greenhouse soils contained OTUs belonging mainly to the phylum Firmicutes and the class Alphaproteobacteria. The orchard soils had indicator taxa belonging to Acidobacteria, in particular, subgroup 6 and the phylum Nitrospirae. The upland soils had only one specific indicator taxon, which belonged to the genus Gemmatimonas.

Of indicator taxa of each agricultural land-use type, the most abundant OTUs were OTU174 (0.94\%), OTU7 $(0.98 \%)$, OTU8 $(0.45 \%)$, and OTU1562 $(0.16 \%)$ in paddy, greenhouse, orchard, and upland soils, respectively (Supplementary Fig. S7). OTU174 was affiliated with Chloroflexi and clustered with uncultured bacterial clones detected in paddy soils. OTU7 was phylogenetically close to Bacillus isolated from the rhizosphere soil of cucumber and tomato, which are the main vegetables grown in greenhouses. OTU8 was affiliated with Nitrospirae and clustered with uncultured bacterial clones observed in soils growing trees and grasses. OTU1562 belongs to Gemmatimonadetes and was clustered with uncultured bacterial clones observed in cropping soils with peanut, tobacco, and vegetables. To conclude, the majority of bacterial communities in soils were not differentiated by the types of agricultural land use, and there were distinct taxa specific to agricultural land use.

Co-occurrence networks of soil bacterial communities in different types of agricultural land use. To explore the complex microbial community structures in different types of agricultural land use, we performed co-occurrence network analysis using molecular ecological network analyses (MENA) based on random-metric theory (RMT). In the network analysis, common OTUs present in $>50 \%$ of samples were used. The network connectivity with a high level of $\mathrm{R}^{2}$ of power-law (>0.7) indicated scale-free properties (Supplementary Table S2). The number of OTUs associated with the networks were the highest in paddy soils and the lowest in upland soils (Fig. 5). The average network distance, referred to as the average path length (GD), was the highest in the network of paddy soils. However, the connectivity between OTUs, referred to as average degree (avgK), were the highest in the network of orchard soils, followed by upland, paddy, and greenhouse soils. The results of network topology showed that relatively large numbers of bacterial taxa in the bacterial communities of paddy and greenhouse soils were associated with the co-occurrence networks but were not densely connected to each other, while relatively low numbers of OTUs associated with the networks of orchard and upland soils tended to be closely connected to each other. 


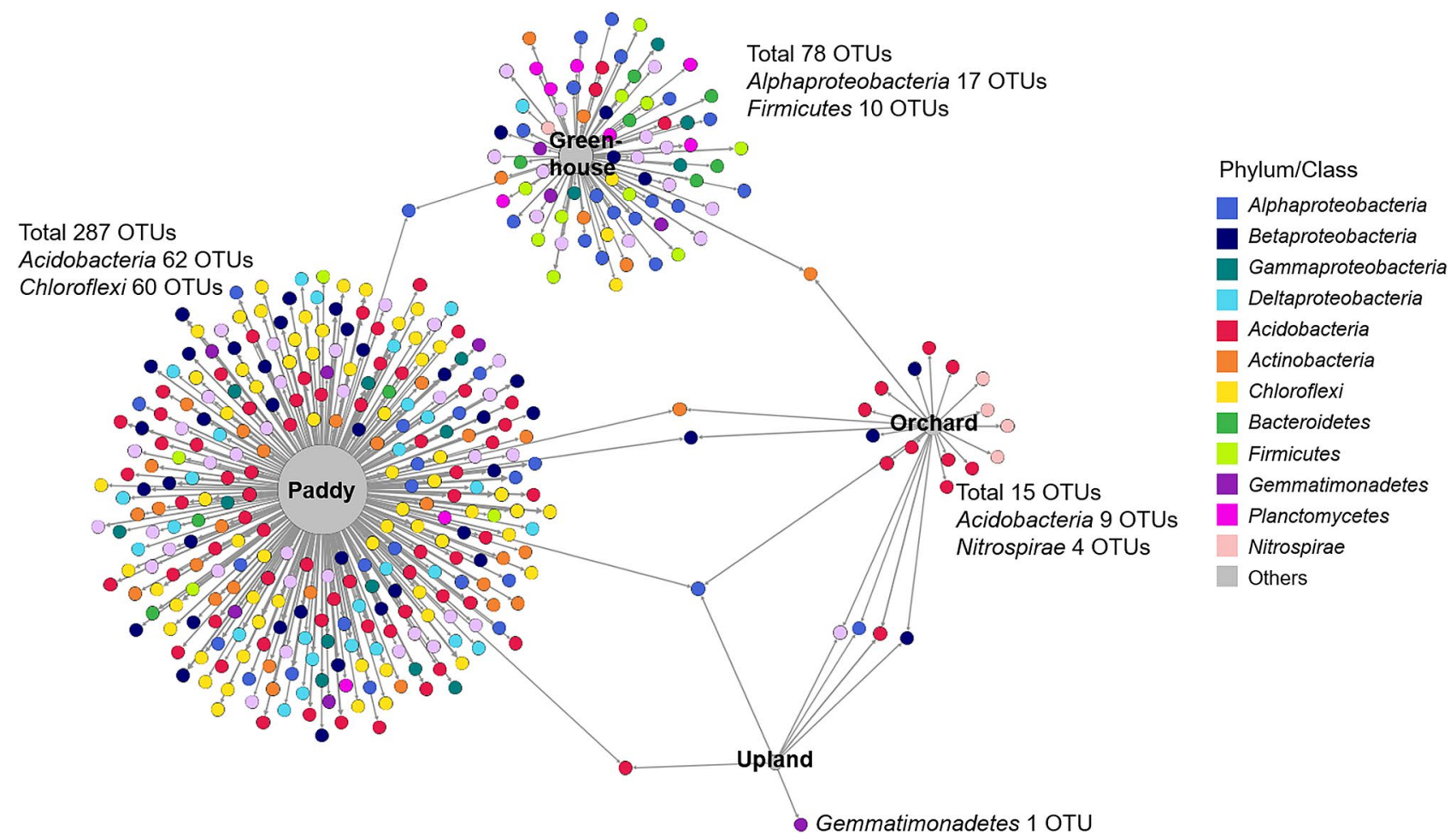

Figure 4. Bipartite network showing the associations between the four types of land use and 391 significantly associated OTUs $(P<0.01)$. Edges (node connection) show the association of individual OTUs with each type of agricultural land use. OTUs are colored by phylum or class. The network analysis was visualized using Gephi 0.9 .1 .

Next, we identified OTUs that have the most frequent interactions with other taxa and the highest value of betweenness centrality in the co-occurrence networks, which are potential keystone taxa playing an important role in a microbial ecosystem. The keystone OTUs also varied with the types of agricultural land use: OTU46927 (phylum Chloroflexi) in paddy soils, OTU37000 (class Gammaproteobacteria) in greenhouse soils, OTU608 and OTU16 (phylum Acidobacteria) in orchard soils, and OTU127 (phylum Acidobacteria) in upland soils (Supplementary Fig. S8). None of them were identified as indicator OTUs that are highly abundant in specific types of agricultural land use, as described above. Most of the indicator OTUs in the networks showed relatively less connectivity with other OTUs (Fig. 5), indicating that keystone taxa with high connectivity are independent of indicator taxa.

\section{Discussion}

In the present study, we investigated soil bacterial distributions across four types of agricultural land use, including greenhouses, orchards, paddy cultivation, and uplands, throughout the Republic of Korea. The bacterial diversities and community structures were clearly differentiated by agricultural land-use type (Fig. 1 and Table 1), which were represented as soil chemical properties, of which paddy soils showed the most distinct characteristics in comparison with the other land-use types; greenhouse soils also had different characteristics from those of orchard and upland soils (Fig. 2 and Table 2). The subset of bacterial taxa in the communities were specific to each land type, which were related to different phylum distributions (Figs. 3 and 4). The bacterial communities in different types of agricultural land use exhibited distinct co-occurrence patterns (Fig. 5).

The type of agricultural land use affects soil bacterial community structures. The bacterial community structures were differentiated by the types of agricultural land use, as observed by NMDS analysis (Fig. 1). These results are consistent with findings reported by previous studies that investigated the responses of bacterial communities to agricultural management, such as conventional versus conservation agriculture practices ${ }^{16,35,36}$. Agricultural management practices such as irrigation, fertilization, tillage, and the application of plant protection chemicals can vary across land-use types depending on the cultivated crops. Our study aimed to conduct a nationwide survey of bacterial distribution across four different types of agricultural land use at large spatial scales; however, the impact of individual management practice on bacterial communities was not investigated. Instead, we hypothesized that the management practices in each type of agricultural land use represent soil chemical properties. Rice paddy fields are unique environments as a flooded parcel of arable land, which can be further divided into oxic surface soil and anoxic bulk soil during rice cultivation ${ }^{37}$. Microscale gradients of oxygen within these soil compartments influence the spatial distribution of microbial communities, leading to the highest bacterial richness and diversity (Table 1), with the most distinguishable community structure 

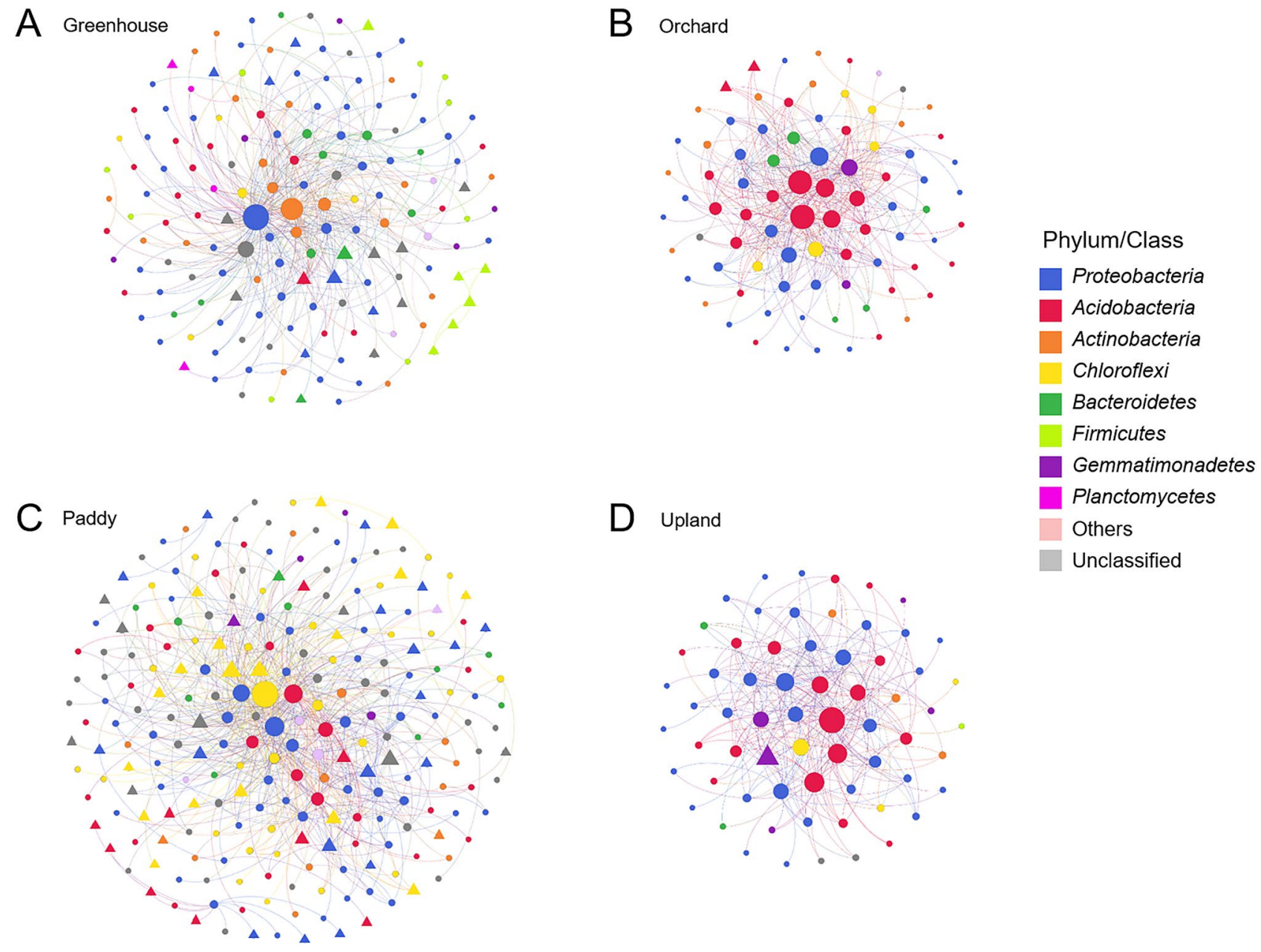

Figure 5. Co-occurrence networks of each type of agricultural land use. Circles and triangles indicate OTUs associated in the network. In particular, triangles represent indicator OTUs analyzed in Fig. 4. The size of circles and triangles is proportional to the number of degrees. OTUs are colored by phylum. The network analysis was visualized using Gephi 0.9.1.

from those of the other land-use types (Fig. 1). It is generally known that bacterial richness and diversity are the highest in neutral soils and lower in acidic soils ${ }^{17}$. We also observed the unimodal diversity patterns in agricultural soils except for paddy soils. Most paddy soils had a rather narrow $\mathrm{pH}$ range (pH 5.0-6.0), which is not sufficiently broad for pattern detection. Although paddy soils had relatively lower $\mathrm{pH}$ values than other land-use types, their higher bacterial richness and diversity might be responsible for the distinct environments supported diverse microbial niches. Greenhouse farming is subject to intensive agricultural material inputs to enhance productivity, resulting in an accumulation of chemical components in the soil, such as available $\mathrm{P}_{2} \mathrm{O}_{5}$ and exchangeable cations ${ }^{38}$. This relates to the distinct chemical properties of greenhouse soils that differentiate it from other land-use types with significantly higher values of EC, available $\mathrm{P}_{2} \mathrm{O}_{5}$, and exchangeable cations (Fig. 2). These chemical factors are known to affect soil microbial community structures ${ }^{31,39-43}$. Although orchard and upland systems cultivated with perennial and annual plants in open fields, respectively, showed similar soil chemical properties (Table 2), crop species can affect soil microenvironments through differences in root exudates or leaf litter produced ${ }^{4}$, leading to different bacterial community structures in various agricultural land-use types. Overall, our results indicate that agricultural management practices corresponding to types of agricultural land use have significant impacts on soil chemical properties and drive variation in bacterial community structures.

Studies have shown that environmental variables generally change with spatial gradients, which are correlated with bacterial biogeography ${ }^{23,32}$. However, the soil chemical properties measured in this study did not show a spatial gradient due to intensive anthropogenic activities applied under each type of agricultural land use for crop cultivation. Variation partitioning analysis, represented by the type of agricultural land use and edaphic variables, were major determinants of bacterial community structure in agricultural soils (Fig. 2). This explains why variations in bacterial communities within each type of agricultural land use were more closely associated with soil chemical properties and that the effects of past dispersal or disturbance events were minimized.

Distribution of bacterial taxa specific to agricultural land-use types. In this study, we aimed to identify OTUs sensitive to agricultural land-use types by performing a correlation-based indicator species 
analysis ${ }^{45}$. We identified 391 OTUs having strong and significant correlations with types of agricultural land use, indicating that specific OTUs are prevalently distributed in their preferred types of agricultural land use. These relationships further suggest ecological attributes of these taxa that are sensitive to environmental conditions of certain agricultural land-use types. In particular, paddy soils had a much greater number of indicator OTUs (287) than other types of agricultural land use. Most of the paddy indicator OTUs were related to the phylum Chloroflexi (Fig. 4), with a relatively higher abundance over the other three types of agricultural land use (Fig. 3). The isolates of Chloroflexi have been detected in anaerobic environments such as sediments, hot springs, and sludge and include mesophilic and thermophilic aerobic and anaerobic chemoheterotrophs ${ }^{46-49}$. Chloroflexi is prevalent in oligotrophic environments, such as nutrient-poor soils ${ }^{50,51}$ and alpine tundra soil ${ }^{52}$. Since flooded paddy fields provide anaerobic conditions and have lower EC, available $\mathrm{P}_{2} \mathrm{O}_{5}$, and exchangeable cations compared to other types of land use, the abundances of Chloroflexi were relatively high in rice paddy soils, consistent with previous studies ${ }^{53-55}$.

Acidobacteria was one of the abundant phyla not only in paddy but also in orchard indicator OTUs. This conflicting relationship implies that soils harbor different compositions of the phylum Acidobacteria at lower taxonomic levels according to agricultural land-use types: orchard-related indicator OTUs mainly comprised subgroup 6, while paddy-related indicator OTUs comprised subgroups 1, 3, 4, 7, 11, 16, and 18. Relationships between acidobacterial abundance and soil chemical properties, such as carbon amendment level and soil $\mathrm{pH}$, have been reported ${ }^{56,57}$. In particular, Navarrete et al. ${ }^{58}$ described Acidobacteria subgroups that exhibited different correlations with soil parameters. For example, Acidobacteria subgroups 1, 2, and 13 had negative relationships with soil properties, such as $\mathrm{pH}, \mathrm{N}, \mathrm{C}, \mathrm{P}, \mathrm{Ca}^{2+}, \mathrm{Mg}^{2+}$, and $\mathrm{K}^{+}$, while Acidobacteria subgroups 4, 5, and 6 were positively correlated with these soil factors. This result is consistent with our finding wherein Acidobacteria subgroups had different distributions in paddy and orchard soils.

Many indicator OTUs in the greenhouse soils were associated with Firmicutes at a relatively higher abundance than that of the other types of agricultural land use (Fig. 4). Their high abundance in greenhouse soils, which contain relatively high levels of edaphic factors, is supported by previous studies that reported the prevalence of Firmicutes in copiotrophic environments, such as agricultural fields with nutrient inputs ${ }^{59}$ and soils with agricultural intensification ${ }^{60}$. In particular, OTU7 (0.98\%), affiliated with Bacillus, was the most abundant among the greenhouse indicator OTUs, which were clustered with Bacillus strains isolated from the rhizosphere or endosphere of vegetables such as tomatoes and cucumbers (Supplementary Fig. S7). Bacillus species are beneficial bacteria well-known to promote plant growth and enhance plant tolerance to abiotic and biotic stresses ${ }^{61}$. Since vegetables grow continuously in greenhouse soils with fertilizers, members of Bacillus closely associated with these plants seem to be predominant in greenhouse soil.

We identified six OTUs that were strongly correlated with sensitivity to EC (Supplementary Fig. S4). They were assigned to Rhodospirillaceae (OTU_4103, OTU_5485, OTU_340, and OTU_505), Rhodobacteraceae (OTU_4767), and Chloroflexi (OTU_269). Rhodospirillaceae and Rhodobacteraceae are families in the subclass Alphaproteobacteria and comprise purple non-sulfur bacteria that are phototrophic in anaerobic environments ${ }^{62,63}$. Although EC was one of the edaphic factors higher in the greenhouse soils, only two OTUs of EC-sensitive OTUs were greenhouse-related indicator OTUs, indicating that in addition to chemical properties of soils, complex factors in different farming systems influence specific OTUs. Our results highlight the potential of these OTUs as applicable biological indicators for monitoring how soil conditions are affected by agricultural managements.

Effects of agricultural land-use type on co-occurrence networks. We explored bacterial co-occurrence patterns in different types of agricultural land use with a large collection of soil samples from across the Republic of Korea. The microbial interactions in networks show the structure and dynamics of soil microbial communities $^{27}$. The members associated with the network and its topologies clearly varied with the types of agricultural land use (Fig. 5, Supplementary Table S2). Consistent with higher species richness in paddy soils, a relatively large number of OTUs were associated with the network of paddy soils. Moreover, the number of modules was the highest in the microbial network of paddy soils. Given that a module is a cluster of densely interconnected nodes and indicates groups of taxa with overlapping niches ${ }^{28}$, it seemed to reflect multiple niches caused by the unique environmental feature of paddy soil. In contrast, microbial networks of orchard soils were relatively small, but the interactions were close to each other. In an analysis of microbial co-occurrence patterns in forest, grassland, crop system, and vineyard soils, the network complexity was found to be lowered by high cropping intensity ${ }^{64}$. As orchards undergo less tillage and fruit trees are continuously grown for several years, the cropping intensity of orchards is relatively lower than that of other agricultural land-use types such as greenhouse and paddy cultivation. This might explain the more complex microbial interactions in orchard soils.

The highly connected OTUs, referred to as keystone taxa, also varied with the types of agricultural land use (Fig. 5 and Fig S3). The keystone taxa in the networks of orchard and upland soils were members of Acidobacteria, which is the phylum enriched in both soils. Given the similar network topology and beta-diversity of bacterial communities in orchard and upland soils, these two agricultural land-use types might have similar agro-ecosystems, which can be inferred from similar chemical properties between the two types. The keystone taxa in the microbial networks of greenhouse and paddy soils were affiliated with Gammaproteobacteria and Chloroflexi, respectively, which were also the relatively more abundant phyla in these soils compared to other soils studied. Although keystone taxa are known to play important roles in microbial communities, the relative abundances of the keystone OTUs were low, and none of them were indicator taxa. Most indicator taxa associated with the microbial networks had a few links. This result is consistent with the study that most indicator OTUs in the soil microbiome with different cropping practices, including organic managements and tillage intensities, were not 
keystone taxa ${ }^{65}$, suggesting that keystone taxa were not significantly affected by environmental disturbances, but those indicator taxa were affected by agricultural activities.

\section{Conclusion}

The soil environment is a dynamic and highly complex system composed of microbes that are affected by various biotic (i.e., earthworms, arthropods, and microbial domains) and abiotic (i.e., precipitation, temperature, humidity, and anthropogenic effects) factors. Our study showed that agricultural land-use types determined bacterial community structures and specific taxa were enriched in specific types of agricultural land use, with distinct correlations with soil chemical properties. Furthermore, microbial interactions based on the co-occurrence patterns in soil bacterial communities also varied with agricultural land-use types. Our findings provide a novel perspective of how land-use type-specific taxa reflect soil conditions and can thus be used as potential biological indicators for maintaining soil health and sustainable crop production. Further research is needed to explore relationships between soil fertility, crop productivity, and microbial community structure, which will help us better understand which bacterial communities or specific taxa support sustainable agricultural management.

\section{Materials and methods}

Soil sampling. Soil sampling was conducted between March 2013 and May 2016 throughout the Republic of Korea (Supplementary Fig. S1 and Supplementary Data S1). Soil samples were collected from the southern regions in March and the northern regions in May to decrease temperature variation, except for the paddy fields, where samples were taken from March to April, before the flood period. A total of 853 soil samples were collected and grouped into four types of agricultural land use, namely, greenhouse, orchard, rice paddy, and upland. Sampling was conducted in the order of uplands (2013), orchards (2014), paddy fields (2015), and greenhouses (2016). At each sampling site, a total of ten soil cores were taken at $10 \mathrm{~m}$ intervals to a depth of $15 \mathrm{~cm}$, pooled together in a sterile plastic bag, and transported to the laboratory in an ice-filled cooler. The latitude and longitude of each sampling site were recorded using a hand-held global positioning system.

Determination of soil physicochemical properties. Soil samples were mixed well and sieved through a $2 \mathrm{~mm}$ mesh. Samples were pre-incubated at $22^{\circ} \mathrm{C}$ for 7 days to reduce environmental disturbances during sampling and sieving ${ }^{66}$ and stored at $-80^{\circ} \mathrm{C}$ until further molecular analysis. Soil $\mathrm{pH}$ and electrical conductivity (EC) were measured using a pH meter (CyberScan pH1500; EUTECH, USA) and an EC meter (D-54; Horiba, Japan), respectively, after shaking the soil/water (1:5) mixture for $30 \mathrm{~min}$ at $200 \mathrm{rpm}$. The organic matter (OM) content was measured using the Walkely and Black method ${ }^{67}$, and the available $\mathrm{P}_{2} \mathrm{O}_{5}$ content was measured by the Lancaster method ${ }^{68}$. Exchangeable cations $\left(\mathrm{Ca}^{2+}, \mathrm{Mg}^{2+}, \mathrm{Na}^{+}\right.$, and $\left.\mathrm{K}^{+}\right)$were extracted with $1 \mathrm{M} \mathrm{NH}_{4} \mathrm{OAc}(\mathrm{pH}$ 7.0) from soil samples and analyzed using inductively coupled plasma atomic emission spectroscopy (ICP-AES; GBC Integra-XMP, Melbourne, Australia).

DNA extraction and 16S rRNA pyrosequencing. DNA was extracted from approximately $0.5 \mathrm{~g}$ of the soil samples in duplicate using the FastDNA SPIN Kit for Soil (MP Biomedicals, Solon, OH, USA) according to the manufacturer's instructions. The DNA extracts were quantified using an ND-1000 spectrophotometer (NanoDrop Technologies, Wilmington, DE, USA). Integrity of DNA was confirmed by running the DNA extracts on a $1.2 \%(\mathrm{w} / \mathrm{v})$ agarose gel with $0.5 \mathrm{X}$ TBE buffer (45 mM Tris-borate, $1 \mathrm{mM}$ EDTA, $\mathrm{pH} 8.0$ ).

PCR amplification, purification, and pyrosequencing of partial 16S rRNA genes were performed at the National Instrumentation Center of Environmental Management (NICEM; Seoul, Republic of Korea) using the 454 GS FLX Titanium Sequencing System (Roche 454 Life Sciences, Branford, CT, USA). Briefly, PCR amplification was performed using the specifically designed fusion primers V1-9F (5'-X-AC-GAGTTTGATCMTGG CTCAG-3') and V3-541R (5'-X-AC-WTTACCGCGGCTGCTGG-3'), which contained linker sequences (AC) and 7-10 barcode sequences, under the following conditions: initial denaturation at $94{ }^{\circ} \mathrm{C}$ for $5 \mathrm{~min}$, followed by 10 cycles of $94^{\circ} \mathrm{C}$ for $30 \mathrm{~s}$ for denaturation, $60^{\circ} \mathrm{C}$ for $45 \mathrm{~s}$ for annealing, and $72{ }^{\circ} \mathrm{C}$ for $90 \mathrm{~s}$ for elongation, with the annealing temperature reduced by $0.5^{\circ} \mathrm{C}$ per cycle from the preceding cycle. Twenty additional cycles of $94{ }^{\circ} \mathrm{C}$ for $30 \mathrm{~s}, 55^{\circ} \mathrm{C}$ for $45 \mathrm{~s}$, and $72^{\circ} \mathrm{C}$ for $90 \mathrm{~s}$ were performed ${ }^{31}$. Each PCR mixture $(50 \mu \mathrm{L})$ included $5 \mu \mathrm{L}$ of $10 \mathrm{X}$ buffer, $1 \mu \mathrm{L}$ of dNTP mix $(10 \mathrm{mM}), 1 \mu \mathrm{L}$ of each fusion primer $(50 \mathrm{pmol}), 40.8 \mu \mathrm{L}$ of sterile deionized $\mathrm{H}_{2} \mathrm{O}$, $1 \mu \mathrm{L}$ of Taq DNA polymerase $(1 \mathrm{U})$, and $1 \mu \mathrm{L}$ of template DNA $(1 \mathrm{ng})$. PCR products were pooled at equimolar concentrations for pyrosequencing reactions.

Analysis of pyrosequencing data. Clustering of $16 \mathrm{~S}$ rRNA amplicon sequence reads into operational taxonomic units (OTUs) was performed using the UPARSE pipeline ${ }^{69}$ with some modifications. Briefly, barcode and primer sequences were removed using the trim.fastq script. Reads shorter than 300 bp were removed, and those longer than $300 \mathrm{bp}$ were properly trimmed. Reads were then clustered into OTUs at a cutoff of 0.03 using the UPARSE-OTU algorithm. Chimeras were removed in de novo and reference modes using UCHIME and USEARCH, respectively. The resulting OTU table was transformed using customized perl scripts for use in the MOTHUR program ${ }^{70}$. Taxonomic assignment was carried out using the classify.seqs command (iters $=1,000$ and cutoff $=60$ ) in the MOTHUR program based on the Ribosomal Database Project database (RDP version 14; https://rdp.cme.msu.edu). After the read number in each sample was normalized to that of the sample with the smallest number of reads (1,002 reads), Good's coverage, richness estimator (abundance-based coverage estimator (ACE) and Chao1), and diversity indices (Shannon and inverse-Simpson) were calculated using the MOTHUR program. 
Bioinformatics analyses. Statistical analyses in this study were performed using the $\mathrm{R}$ program ver. 3.3.1; R Core Team ${ }^{71}$. Variations in bacterial community structures among the different land-use types were visualized using non-metric multidimensional scaling (NMDS) based on the Bray-Curtis distance of Hellingertransformed OTU numbers using metaMDS and decostand functions in the vegan package. The dispersion of bacterial communities was measured using the betadisper function in the vegan package. Analysis of similarities (ANOSIM) and permutational multivariate analysis of variance (PERMANOVA) were performed for pair-wise comparisons of soil microbial communities with four different types of agricultural land use using the anosim and adonis functions in the R package vegan, respectively. Soil chemical parameters were log-transformed for normal distribution, while raw data was used for $\mathrm{pH}$, and variations were visualized using principal component analysis (PCA). The constrained ordination analysis of bacterial communities by soil chemical properties was performed using redundancy analysis (RDA) with the $r d a$ function in the R package. The correlation between soil chemical properties and relative abundances of OTUs were examined using the cor.test function based on Pearson's correlation method. The statistical analysis of distance-decay patterns, and the relationship between bacterial diversity and soil $\mathrm{pH}$ were performed using quadratic regression. Variation partitioning analysis was performed using the varpart function in the vegan $\mathrm{R}$ package to assess the relative influence of edaphic variables, land-use type, and geographic distance on bacterial community structures. To perform spatially explicit multiscale modeling, spatial variables were calculated using the MEMs approach in adespatial R package $\mathrm{e}^{72}$. The connectivity matrix (relative neighborhood) weighted by the Euclidian distance function was generated, followed by a forward selection procedure that was used to select the set of MEM variables which best explained the community variation based on adjusted the $R^{2}$ statistics.

To identify the OTUs that were specifically abundant in each type of agricultural land use, indicator species analysis was conducted using the multipatt function with the r.g option in the R package indispecies. The strength of association of each OTU with a particular agricultural land-use type or its combinations was represented as a point-biserial correlation coefficient $R$ using correlation-based indicator species analysis ${ }^{45}$. The false discovery rate (FDR) was used for multiple comparison correction ${ }^{73}$ using the R package FSA ${ }^{74}$. The bipartite network was visualized with Gephi 0.9.1 ${ }^{75}$.

Co-occurrence network analysis was conducted using molecular ecological network analyses (MENA) based on random-metric theory $(\mathrm{RMT})^{76}$. To reduce environmental disturbance, datasets were separated by the types of agricultural land use, and OTUs detected in $>50 \%$ of samples were used in the analysis. The detailed options of MENA were as follows: 0.01 was filled in the blanks with paired valid values; logarithm values were obtained; Pearson's correlation coefficient was used for correlation analysis; and calculations were done by decreasing the cutoff from the top with Poisson regression only. A similarity threshold was selected automatically by the RMT-based approach to define the adjacency matrix. The results of the network analysis were visualized using Gephi 0.9.1 $1^{75}$.

\section{Data availability}

Raw pyrosequencing data obtained in this study were deposited in the NCBI Sequence Read Archive (https:// www.ncbi.nlm.nih.gov/sra) with the accession number PRJNA499124.

Received: 7 April 2020; Accepted: 20 August 2020

Published online: 15 October 2020

\section{References}

1. Marschner, P., Crowley, D. \& Yang, C. H. Development of specific rhizosphere bacterial communities in relation to plant species, nutrition and soil type. Plant Soil 261, 199-208 (2004).

2. Osler, G. H. R. \& Sommerkorn, M. Toward a complete soil C and N cycle: Incorporating the soil fauna. Ecology 88, 1611-1621 (2007).

3. Kennedy, A. C. Bacterial diversity in agroecosystems. Agric. Ecosyst. Environ. 74, 65-76 (1999).

4. Mendes, R., Garbeva, P. \& Raaijmakers, J. M. The rhizosphere microbiome: Significance of plant beneficial, plant pathogenic, and human pathogenic microorganisms. FEMS Microbiol. Rev. 37, 634-663 (2013).

5. van der Heijden, M. G. A., Bardgett, R. D. \& van Straalen, N. M. The unseen majority: soil microbes as drivers of plant diversity and productivity in terrestrial ecosystems. Ecol. Lett. 11, 296-310 (2008).

6. Drenovsky, R. E., Steenwerth, K. L., Jackson, L. E. \& Scow, K. M. Land use and climatic factors structure regional patterns in soil microbial communities. Glob. Ecol. Biogeogr. 19, 27-39 (2010).

7. Ma, B. et al. Distinct biogeographic patterns for archaea, bacteria, and fungi along the vegetation gradient at the continental scale in Eastern China. mSystems 2, e00174-e1116 (2017).

8. Wang, X. B. et al. Habitat-specific patterns and drivers of bacterial beta-diversity in China's drylands. ISME J. 11, 1345-1358 (2017).

9. Sala, O. E. et al. Global biodiversity scenarios for the year 2100. Science 287, 1770-1774 (2000).

10. Singh, J. S., Pandey, V. C. \& Singh, D. P. Efficient soil microorganisms: A new dimension for sustainable agriculture and environmental development. Agric. Ecosyst. Environ. 140, 339-353 (2011).

11. Verhulst, N. et al. Soil quality as affected by tillage-residue management in a wheat-maize irrigated bed planting system. Plant Soil 340, 453-466 (2011).

12. Aziz, I., Mahmood, T. \& Islam, K. R. Effect of long term no-till and conventional tillage practices on soil quality. Soil Tillage Res. 131, 28-35 (2013).

13. Navarro-Noya, Y. E. et al. Relative impacts of tillage, residue management and crop-rotation on soil bacterial communities in a semi-arid agroecosystem. Soil Biol. Biochem. 65, 86-95 (2013).

14. Meriles, J. M. et al. Soil microbial communities under different soybean cropping systems: Characterization of microbial population dynamics, soil microbial activity, microbial biomass, and fatty acid profiles. Soil Tillage Res. 103, 271-281 (2009).

15. Chaudhry, V., Rehman, A., Mishra, A., Chauhan, P. S. \& Nautiyal, C. S. Changes in bacterial community structure of agricultural land due to long-term organic and chemical amendments. Microb. Ecol. 64, 450-460 (2012).

16. Hartmann, M., Frey, B., Mayer, J., Mader, P. \& Widmer, F. Distinct soil microbial diversity under long-term organic and conventional farming. ISME J. 9, 1177-1194 (2015). 
17. Fierer, N. \& Jackson, R. B. The diversity and biogeography of soil bacterial communities. Proc. Natl. Acad. Sci. USA. 103, 626-631 (2006).

18. Bartram, A. K. et al. Exploring links between $\mathrm{pH}$ and bacterial community composition in soils from the Craibstone experimental farm. FEMS Microbiol. Ecol. 87, 403-415 (2014).

19. Min, W. et al. Response of soil microbial community and diversity to increasing water salinity and nitrogen fertilization rate in an arid soil. Acta Agric. Scand. B Soil Plant Sci. 66, 117-126 (2016).

20. Lauber, C. L., Strickland, M. S., Bradford, M. A. \& Fierer, N. The influence of soil properties on the structure of bacterial and fungal communities across land-use types. Soil Biol. Biochem. 40, 2407-2415 (2008).

21. Lozupone, C. A. \& Knight, R. Global patterns in bacterial diversity. Proc. Natl. Acad. Sci. USA. 104, 11436-11440 (2007).

22. Zhang, X.-Y., Sui, Y.-Y., Zhang, X.-D., Meng, K. \& Herbert, S. J. Spatial variability of nutrient properties in black soil of Northeast China. Pedosphere 17, 19-29 (2007).

23. Griffiths, R. I. et al. The bacterial biogeography of British soils. Environ. Microbiol. 13, 1642-1654 (2011).

24. Liu, J. et al. High throughput sequencing analysis of biogeographical distribution of bacterial communities in the black soils of northeast China. Soil Biol. Biochem. 70, 113-122 (2014).

25. Kim, M. et al. Highly heterogeneous soil bacterial communities around Terra Nova Bay of northern Victoria, Land Antarctica. PLOS ONE 10, e0119966 (2015).

26. Hermans, S. M. et al. Bacteria as emerging indicators of soil condition. Appl. Environ. Microbiol. 83, e02826-e12816 (2017).

27. Barberan, A., Bates, S. T., Casamayor, E. O. \& Fierer, N. Using network analysis to explore co-occurrence patterns in soil microbial communities. ISME J. 6, 343-351 (2012).

28. Faust, K. \& Raes, J. Microbial interactions: from networks to models. Nat. Rev. Microbiol. 10, 538-550 (2012).

29. van der Heijden, M. G. \& Hartmann, M. Networking in the plant microbiome. PLoS Biol. 14, e1002378 (2016).

30. Shi, S. et al. The interconnected rhizosphere: High network complexity dominates rhizosphere assemblages. Ecol. Lett. 19, 926-936 (2016).

31. Kim, J. M. et al. Soil $\mathrm{pH}$ and electrical conductivity are key edaphic factors shaping bacterial communities of greenhouse soils in Korea. J. Microbiol. 54, 838-845 (2016).

32. Tripathi, B. et al. Spatial scaling effects on soil bacterial communities in Malaysian tropical forests. Microb. Ecol. 68, 247-258 (2014).

33. Feng, M. et al. Interpreting distance-decay pattern of soil bacteria via quantifying the assembly processes at multiple spatial scales. MicrobiologyOpen 8, e00851 (2019).

34. Morlon, H. et al. A general framework for the distance-decay of similarity in ecological communities. Ecol. Lett. 11, 904-917 (2008).

35. Figuerola, E. L. M. et al. Bacterial indicator of agricultural management for soil under no-till crop production. PLoS ONE 7, e51075 (2012).

36. Jimenez-Bueno, N. G. et al. Bacterial indicator taxa in soils under different long-term agricultural management. J. Appl. Microbiol. 120, 921-933 (2016).

37. Liesack, W., Schnell, S. \& Revsbech, N. P. Microbiology of flooded rice paddies. FEMS Microbiol. Rev. 24, 625-645 (2000).

38. Kang, S. S. et al. Status and change in chemical properties of polytunnel soil in Korea from 2000 to 2012. Korean J. Soil Sci. Fertil. 46, 641-646 (2013).

39. Handley, K. M. et al. High-density PhyloChip profiling of stimulated aquifer microbial communities reveals a complex response to acetate amendment. FEMS Microbiol. Ecol. 81, 188-204 (2012).

40. Ma, J. C., Ibekwe, A. M., Yang, C. H. \& Crowley, D. E. Bacterial diversity and composition in major fresh produce growing soils affected by physiochemical properties and geographic locations. Sci. Total Environ. 563, 199-209 (2016).

41. Reich, P. B. et al. Linking litter calcium, earthworms and soil properties: A common garden test with 14 tree species. Ecol. Lett. 8, 811-818 (2005).

42. Sridevi, G. et al. Soil bacterial communities of a calcium-supplemented and a reference watershed at the Hubbard Brook experimental forest (HBEF), New Hampshire, USA. FEMS Microbiol. Ecol. 79, 728-740 (2012).

43. Singh, D., Shi, L. \& Adams, J. M. Bacterial diversity in the mountains of South-West China: Climate dominates over soil parameters. J. Microbiol. 51, 439-447 (2013).

44. Miethling, R., Wieland, G., Backhaus, H. \& Tebbe, C. C. Variation of microbial rhizosphere communities in response to crop secies, soil origin, and inoculation with Sinorhizobium meliloti L33. Microb. Ecol. 40, 43-56 (2000).

45. De Caceres, M. \& Legendre, P. Associations between species and groups of sites: Indices and statistical inference. Ecology $\mathbf{9 0}$, 3566-3574 (2009).

46. Oyaizu, H., Debrunner-Vossbrinck, B., Mandelco, L., Studier, J. A. \& Woese, C. R. The green non-sulfur bacteria: A deep branching in the eubacterial line of descent. Syst. Appl. Microbiol. 9, 47-53 (1987).

47. Rappe, M. S. \& Giovannoni, S. J. The uncultured microbial majority. Annu. Rev. Microbiol. 57, 369-394 (2003).

48. Krzmarzick, M. J. et al. Natural niche for organohalide-respiring Chloroflexi. Appl. Environ. Microbiol. 78, 393-401 (2012).

49. Speirs, L. B. M., Rice, D. T. F., Petrovski, S. \& Seviour, R. J. The phylogeny, biodiversity, and ecology of the chloroflexi in activated sludge. Front. Microbiol.10 (2019).

50. Janssen, P. H. Identifying the dominant soil bacterial taxa in libraries of $16 \mathrm{~S}$ rRNA and 16S rRNA genes. Appl. Environ. Microbiol. 72, 1719-1728 (2006).

51. Will, C. et al. Horizon-specific bacterial community composition of German grassland soils, as revealed by pyrosequencing-based analysis of 16S rRNA genes. Appl. Environ. Microbiol. 76, 6751-6759 (2010).

52. Costello, E. K. \& Schmidt, S. K. Microbial diversity in alpine tundra wet meadow soil: novel Chloroflexi from a cold, water-saturated environment. Environ. Microbiol. 8, 1471-1486 (2006).

53. Lee, H. J., Jeong, S. E., Kim, P. J., Madsen, E. \& Jeon, C. O. High resolution depth distribution of Bacteria, Archaea, methanotrophs, and methanogens in the bulk and rhizosphere soils of a flooded rice paddy. Front. Microbiol. 6, 639 (2015).

54. Ahn, J. H. et al. Dynamics of bacterial communities in rice field soils as affected by different long-term fertilization practices. J. Microbiol. 54, 724-731 (2016).

55. Hernández, M., Conrad, R., Klose, M., Ma, K. \& Lu, Y. Structure and function of methanogenic microbial communities in soils from flooded rice and upland soybean fields from Sanjiang plain NE China. Soil Biol. Biochem. 105, 81-91 (2017).

56. Fierer, N., Bradford, M. A. \& Jackson, R. B. Toward an ecological classification of soil bacteria. Ecology 88, 1354-1364 (2007)

57. Jones, R. T. et al. A comprehensive survey of soil acidobacterial diversity using pyrosequencing and clone library analyses. ISME J. 3, 442-453 (2009).

58. Navarrete, A. A. et al. Differential response of Acidobacteria subgroups to forest-to-pasture conversion and their biogeographic patterns in the western Brazilian Amazon. Front. Microbiol. 6, 1443 (2015).

59. Leff, J. W. et al. Consistent responses of soil microbial communities to elevated nutrient inputs in grasslands across the globe. Proc. Natl. Acad. Sci. USA. 112, 10967-10972 (2015).

60. Trivedi, P., Delgado-Baquerizo, M., Anderson, I. C. \& Singh, B. K. Response of soil properties and microbial communities to agriculture: Implications for primary productivity and soil health indicators. Front. Plant Sci. 7, 990 (2016).

61. Radhakrishnan, R., Hashem, A. \& Abd Allah, E. F. Bacillus: A biological tool for crop improvement through bio-molecular changes in adverse environments. Front. Physiol. 8, 667 (2017). 
62. Pujalte, M. J., Lucena, T., Ruvira, M. A., Arahal, D. R. \& Macián, M. C. The Family Rhodobacteraceae. In The Prokaryotes (eds Rosenberg, E. et al.) 439-512 (Springer, Berlin, 2014).

63. Baldani, J. I. et al. The Family Rhodospirillaceae. In The Prokaryotes (eds Rosenberg, E. et al.) 533-618 (Springer, Berlin, 2014).

64. Karimi, B. et al. Biogeography of soil bacterial networks along a gradient of cropping intensity. Sci. Rep. 9, 3812 (2019).

65. Hartman, K. et al. Cropping practices manipulate abundance patterns of root and soil microbiome members paving the way to smart farming. Microbiome 6, 14 (2018).

66. Nielsen, M. N. \& Winding, A. Microorganisms as indicators of soil health. National Environmental Research Institute, Denmark, Technical Report no. 388 (2002).

67. Allison, L. E. Organic carbon in Methods of Soil Analysis, Part 2, Chemical and Microbiological Properties (ed Black, C. A.) 1367-1378 (American Society of Agronomy, 1965).

68. National Institute of Agricultural Science and Technology (NIAST). Methods of analysis of soil and plant. (NIAST, 2000)

69. Edgar, R. C. UPARSE: Highly accurate OTU sequences from microbial amplicon reads. Nat. Methods 10, 996-998 (2013).

70. Schloss, P. D. et al. Introducing mothur: Open-source, platform-independent, community-supported software for describing and comparing microbial communities. Appl. Environ. Microbiol. 75, 7537-7541 (2009).

71. R Core Team. R: a language and environment for statistical computing. https://www.R-project.org/ (2016).

72. Dray, S. et al. Community ecology in the age of multivariate multiscale spatial analysis. Ecol. Monogr. 82, 257-275 (2012).

73. Benjamini, Y. \& Hochberg, Y. Controlling the false discovery rate: A practical and powerful approach to multiple testing. J. R Stat. Soc. Series B Stat. Methodol. 57, 289-300 (1995).

74. Ogle, D. H. FSA: Fisheries stock analysis. R package version 0.8.13. (2017).

75. Bastian, M., Heymann, S. \& Jacomy, M. Gephi: an open source software for exploring and manipulating networks. International AAAI Conference on Weblogs and Social Media (2009).

76. Deng, Y. et al. Molecular ecological network analyses. BMC Bioinform. 13, 113 (2012).

\section{Acknowledgements}

This work was carried out with the support of the "Cooperative Research Program for Agricultural Science \& Technology Development (Project No. PJ01093903)", Rural Development Administration, Republic of Korea. We thank An-Sung Roh from Gyeonggido Agricultural Research \& Extension Service (ARES), Seung-Chul Choi from Gangwondo ARES, Eun-Jeong Kim from Chungcheongbukdo ARES, Moon-Tae Choi from Chungcheongnamdo ARES, Byung-Koo Ahn from Jeollabukdo ARES, Sun-Kuk Kim from Jeollanamdo ARES, and Young-Han Lee from Gyeongsangnamdo ARES, Republic of Korea for assistance with soil sampling.

\section{Author contributions}

S.A.L., J.M.K., and H.-Y.W. designed the experiments. S.A.L., J.M.K., H.-Y.W., and Y.K. wrote the manuscript. S.A.L., J.M.K., and M.K. analyzed the data. S.-S.K. and H.-Y.W. collected agricultural soils used in this study. J.H.J. assessed physiochemical properties of soil samples. J.S., J.-H.A., M.K.S., and Y.K. discussed the results and commented on the manuscript. All the authors contributed towards writing the manuscript.

\section{Competing interests}

The authors declare no competing interests.

\section{Additional information}

Supplementary information is available for this paper at https://doi.org/10.1038/s41598-020-74193-8.

Correspondence and requests for materials should be addressed to H.-Y.W.

Reprints and permissions information is available at www.nature.com/reprints.

Publisher's note Springer Nature remains neutral with regard to jurisdictional claims in published maps and institutional affiliations.

Open Access This article is licensed under a Creative Commons Attribution 4.0 International License, which permits use, sharing, adaptation, distribution and reproduction in any medium or format, as long as you give appropriate credit to the original author(s) and the source, provide a link to the Creative Commons licence, and indicate if changes were made. The images or other third party material in this article are included in the article's Creative Commons licence, unless indicated otherwise in a credit line to the material. If material is not included in the article's Creative Commons licence and your intended use is not permitted by statutory regulation or exceeds the permitted use, you will need to obtain permission directly from the copyright holder. To view a copy of this licence, visit http://creativecommons.org/licenses/by/4.0/.

(C) The Author(s) 2020 